\title{
Genetic information, insurance and a pluralistic approach to justice
}

\author{
Jonathan Pugh
}

The Oxford Uehiro Centre for Practical Ethics, University of Oxford, Oxford OX1 1PT, UK

\section{Correspondence to}

Dr Jonathan Pugh, University of Oxford, Oxford OX1 2JD, UK;

jonathan.pugh@philosophy. ox.ac.uk

Received 16 September 2020 Revised 6 March 2021 Accepted 20 March 2021 Published Online First 15 April 2021

\section{Linked}

- http://dx.doi.org/10.1136/ medethics-2021-107538

- http://dx.doi.org/10.1136/ medethics-2021-107539

- http://dx.doi.org/10.1136/ medethics-2021-107542

- http://dx.doi.org/10.1136/ medethics-2021-107645

Check for updates

(c) Author(s) (or their employer(s)) 2021. No commercial re-use. See rights and permissions. Published by BMJ.

To cite: Pugh J. J Med Ethics 2021;47:473-479.

\section{ABSTRACT}

The use of genetic testing has prompted the question of whether insurance companies should be able to use predictive genetic test results (GTRs) in their risk classification of clients. While some jurisdictions have passed legislation to prohibit this practice, the UK has instead adopted a voluntary code of practice that merely restricts the ways in which insurance companies may use GTRs. Critics have invoked various theories of justice to argue that this approach is unfair. However, as well as sometimes relying on somewhat idealised assumptions, these analyses have tended to invoke theories that have wide-ranging and highly revisionary implications for insurance. Moreover, they fail to adequately engage with a conception of justice that plausibly undergirds the status quo approach to insurance in the UK. I argue that it is a mistake to simply invoke a single contestable theory in seeking to develop sound policy on the use of GTRs in insurance. To that end, in this paper, I outline three plausible principles of justice that policy on this issue ought to balance: A principle of equity, a principle of equal access and a principle of need. In doing so, I shall offer a pluralist justice-based argument in support of the spirit, if not the precise letter, of the UK approach.

Genetic test results (GTRs) can provide clinicians with invaluable diagnostic and predictive information about an individual's risk for various health conditions. As National Health Service (NHS) England continues to promote the development of genomic medicine, it is likely that the amount of genetic information appearing on patients' medical records shall substantially increase. While this will hopefully have beneficial effects on patient care, a number of ethical concerns have been raised about this development. One is that insurance companies might access individuals' GTRs and take them into account when categorising individuals into risk pools that determine the cost of obtaining insurance. A number of European countries prohibit this practice, in accordance with the Oviedo Convention. ${ }^{1}$ In contrast, the UK government has adopted a voluntary Code of Practice (henceforth 'the Code') with the Association of British Insurers, which permits the limited use of GTRs in risk classification. ${ }^{2}$

Ethical objections to the use of GTRs in insurance tend to be based on one of two concerns. The first relates to the way in which it would potentially violate a right to genetic privacy. ${ }^{3}$ Since insurers typically have access to other forms of potentially sensitive medical information, this objection tends to incorporate a central tenet of the so-called genetic exceptionalist view, ${ }^{4}$ according to which there is something special about genetic information, such that we have a particularly robust right to privacy regarding it. The challenge facing this argument is to provide an account of the special value of genetic information, one that does not collapse into a problematic form of genetic essentialism, the view that we humans are reducible to our genetic traits. $^{35}$

Whatever the merits of this objection, I shall not be concerned with it here. Instead, I shall focus my attention on the objection that allowing insurers to access GTRs would amount to a form of injustice. Of course, this objection similarly faces the challenge of explaining how insurers' accessing GTRs would raise issues of justice in a manner that their accessing other forms of information need not. I shall consider one reason for why this might be the case below.

Quite different theories of justice have been invoked to support the view that it would be unfair for insurers to use GTRs in risk classification. ${ }^{1}{ }^{35-7}$ Indeed, Martin O'Neill has suggested there will be 'broad convergence from any plausible account of the demands of social justice' on policy options that ensure the absence of genetic discrimination in access to insurance, while safeguarding the individual's right to access her own GTRs. ${ }^{6}$ Indeed, much of the current debate on the topic concerns which theory of social justice best supports this view. ${ }^{135-7}$

However, as well as sometimes relying on somewhat idealised assumptions about the predictive power of GTRs, these analyses have tended to invoke theories of justice that have highly revisionary implications for the provision of insurance beyond the use of GTRs, implications that will garner only as much support as the underlying theories themselves. Furthermore, they fail to adequately engage with a conception of justice that plausibly undergirds the status quo approach to protection insurance in the UK. Since there is room for reasonable disagreement about what constitutes the correct theory of justice, we should not invoke a single contestable theory of justice in seeking to develop policy in this area. Instead, I suggest that we should adopt a pluralistic approach to justice that elucidates the conflicting conceptions of fairness that are relevant to our assessment of what justice demands here.

To that end, in this paper, I shall outline three broad principles of justice that should be balanced in order to guide policy on this issue: A principle of equity, a principle of equality and a principle of need. In doing so, I offer a pluralist justice-based argument in support of the spirit, if not the precise letter, of the Code. To begin, I shall distinguish two different kinds of insurance, and outline key commitments of the Code. 


\section{MUTUALISTIC INSURANCE, SOCIAL INSURANCE, ADVERSE SELECTION AND THE CODE}

The function of insurance is to enable individuals to protect themselves against unexpected harms that they may not otherwise be able to individually afford. Insurance providers perform this function by pooling together financial contributions from a large number of people, thereby spreading the risks and costs of unexpected harmful events.

Following O'Neill, we can distinguish two broad models of insurance provision: social insurance schemes and mutualistic insurance schemes. ${ }^{6}$ Crucially, concerns about insurers' access to GTRs only arise on the latter; on the former, neither the cost of participation, nor an individual's level of insurance cover is dependent on the individual's risk profile. Rather, contributions to social insurance schemes are determined on some other basis (such as income). Participation is often mandatory and enforced by the state, and everyone in the scheme receives the same level of cover. ${ }^{6}$ The NHS is a paradigm example of a social health insurance scheme. In contrast, on mutualistic insurance schemes, the amount of cover an individual can receive and/ or the premium they pay for it depends on their personal risk profile. Such schemes are typically voluntary and run by private companies. $^{6}$

In order for a market of mutualistic insurance schemes to function, insurance companies must be able perform reasonably accurate risk classification. Problems arise if they are significantly less informed about their clients' risk profiles than the clients themselves. In such circumstances, the phenomenon of 'adverse selection' becomes likely, whereby individuals who are aware that they are at high risk are able to purchase insurance policies at the cheaper rates that companies reserve for clients who are believed to be low-risk. ${ }^{1689}$ While a specific instance of adverse selection (ie, in which only one individual high-risk client is better informed than the insurance company) can be in the interests of that individual client, general widespread adverse selection can have devastating effects. In the short term, it increases costs for the insurance company, as it has to pay out on more claims for individuals they have categorised into the 'low risk' pool. To compensate for this, the company will likely increase the premiums for the low risk pool, disincentivising those who are actually low-risk from purchasing insurance from that company. Eventually, this can lead to spiralling costs across the market, and market failure. ${ }^{1}$

GTRs are most plausibly relevant to accurate risk classification for mutualistic schemes that offer cover against health conditions that might lead to financial hardship. Indeed, the Code only permits the use of GTRs for Life Insurance, Critical Illness Insurance and Income Protection Insurance. ${ }^{2}$ Henceforth, I shall use the term 'insurance' to cover solely these kinds of insurance, unless stated otherwise. Notably, as healthcare provision is based on a social insurance model in the UK, debates about using GTRs in risk assessments for health insurance are not as salient in the UK as they are elsewhere. ${ }^{9}$

The Code has the following noteworthy features. First, the limitations it recommends on the use of GTRs only pertain to predictive GTRs, and not diagnostic GTRs. The use of diagnostic GTRs is permitted on the same basis that diagnostic results from other medical tests (such as blood tests) can be used to price insurance. I shall say more on this below. At this point though, it is worth noting that the line between predictive and diagnostic testing is likely to become increasingly blurred, as outputs from genomic sequencing will often incorporate both predictive and diagnostic elements, with a range of predictive certainty. ${ }^{i}$ Of course, the greater the certainty associated with the predictive test, the more useful it will be in developing accurate risk classifications, and this will have important implications for justice, as I shall detail below.

Second, the Code includes separate provisions for the use of GTRs that clients have proactively disclosed. ${ }^{2}$ In the interests of brevity, I set these aside; when I refer to the 'use' of GTRs, I mean to refer to the criteria the Code sets out for the limited circumstances in which insurers 'may ask applicants to disclose the result of a predictive genetic test and take the result of that test into account'.2

Third, with respect to the types of insurance outlined above, the Code employs a two-pronged test for when insurers may ask applicants to disclose predictive GTRs: (1) The policy for which disclosure is requested must be above financial thresholds specific to each type of insurance $(£ 30000$ per annum per person for Income Protection Insurance, $£ 300000$ per person for critical illness insurance and $£ 500000$ per person for life insurance), and (2) The GTR must pertain to a condition that has been approved as relevant under the Code. ${ }^{2}$

To date, the only test results that have been so approved are Huntington's disease GTRs in applications for life insurance cover over the financial limit of $£ 500000$. Initially, this may seem surprising, given the variety of genetic tests available for different disorders and their apparent power. However, predictive GTRs only provide useful information that is necessary for accurate risk classification if they concern disorders serious enough to generate a need for insurance that also:

1. Have an onset after the age of insurance application.

2. Have no treatments to ameliorate the course of the disease.

3. Can be predicted with sufficient accuracy using a genetic test. Crucially, many GTRs fail to meet these criteria.

It is possible that more conditions will be added to the Code's list as technology and understanding advances. Furthermore, the Code is likely to come under significant pressure as whole genome sequencing begins to be integrated into the NHS. It is thus apposite to consider the arguments concerning the just use of GTRs in insurance, particularly in view of the opening sentence of the commitments in the Code, which reads: 'Insurers will always treat applicants fairly'. What might this mean, and does the Code make good on this commitment?

\section{THE PRINCIPLE OF EQUITY AND ACTUARIAL FAIRNESS}

The Code endorses a particular view of fairness. The introductory comments state that 'it is important for insurers to access proportionate levels of relevant health information... so that they can offer fairly priced insurance'. ${ }^{2}$ These comments imply a commitment to an actuarial conception of fairness, underpinned by a principle of equity that can be formulated as follows:

Principle of Equity: Policy-holders should make financial contributions that are commensurate to their degree of risk. ${ }^{\text {iii }}$

${ }^{\mathrm{i}}$ I thank an anonymous reviewer for raising this point.

${ }^{i i}$ For alternative criteria for Life Insurance, see Rothstein. ${ }^{10}$ Rothstein suggests that there must be 'a lack of family history' if a GTR is to provide useful information for insurers. However, this seems too strong-GTRs may provide accurate information that may usefully supplement information from a family history, and family history may even provide the justification for the performance of the test in the first place. I thank the reviewers for urging greater clarity on these criteria.

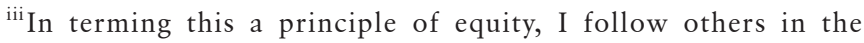


This principle articulates the thought that fairness can require that individuals 'pay their dues'; perhaps those at high risk should pay more because they are more likely to draw on the pooled resources. If a scheme does not stratify premiums in accordance with risk, then low-risk clients effectively subsidise those at high risk.

So understood, the principle articulates a model of actuarial fairness that buttresses the use of mutualistic insurance schemes; it also implies that low-risk individuals should not subsidise high-risk individuals, and that even specific instances of adverse selection involve unfairness. However, for reasons I shall explain further below, many theories of justice deny these claims. On such approaches, actuarial fairness is to be distinguished from moral fairness.

Indeed, some argue the two are quite distinct concepts; for instance, Norman Daniels claims that the former is neither necessary nor sufficient for the latter. ${ }^{7}$ However, further nuance is required here. This view might be true when we conceive of insurance in broad terms to incorporate both social and mutualistic schemes. If one maintains, as Daniels does, that moral fairness requires a social rather than mutualistic insurance scheme, then actuarial fairness cannot be necessary for the moral fairness of that scheme. The simple reason for this is that such schemes eschew risk classification; we can therefore hardly expect individuals to pay premiums that are commensurate to their (unknown) degree of risk.

Nonetheless, if (contra Daniels) we assume that moral fairness is compatible with a mutualistic scheme, then some forms of actuarial fairness in a mutualistic scheme will plausibly be necessary for its moral fairness for a number of reasons. First, actuarial unfairness may occur if companies perform risk assessment based on faulty information, generating false-positive risk profiles that result in individuals being charged higher premiums on the basis of risks that they do not pose. Indeed, this is a particularly salient concern with respect to the use of GTRs. ${ }^{10}$ Second, adverse selection represents another way in which a mutualistic scheme can fail to abide by the principle of equity; while some theories may not classify specific instances of adverse selection as instances of significant injustice, the potentially significant costs of market collapse following general adverse selection would plausibly be an unfair outcome on most plausible understandings of justice, since it would threaten to take away everybody's access to the goods of insurance. ${ }^{1}$

Despite this, there is not a straightforward argument from the principle of equity to the claim that insurers ought to use GTRs in mutualistic schemes. An advocate of permitting the use of GTRs might claim that they raise issues of justice that other forms of information do not because (A) An informational asymmetry between insurers and clients about GTRs is very likely, and (B) This asymmetry will be particularly susceptible to adverse selection, more so than asymmetries regarding other kinds of medically relevant information. However, while the prevalence of direct-to-consumer genetic testing makes a widespread informational asymmetry possible, there are two reasons for supposing that the asymmetry may not entail adverse selection. First, many GTRs lack the predictive power that is necessary for accurate risk assessment, failing at least one of the criteria outlined in the previous section. Second, there is no evidence

literature in inferring 'equity' in a sense that distinguishes equity from all things considered fairness and impartiality. See Godard et al. ${ }^{30}$ The sense I infer is familiar from the use of the term in financial contexts to refer to the value of a company owned by shareholders. of adverse selection in countries that have prohibited the use of GTRs in insurance risk classification. ${ }^{10}$ This argument in favour of using GTRs may thus rely on a somewhat idealised sense of their predictive power.

Of course, this should not be taken to preclude the possibility that threats of general adverse selection might arise in the future, as testing becomes more accurate and widespread. ${ }^{1}$ However, it is sufficient to note here that the principle of equity currently offers only qualified support for permitting the use of GTRs in insurance risk classification. In the next sections, I shall turn to two further principles of justice that may be invoked to oppose this practice.

\section{THE PRINCIPLE OF EQUAL ACCESS AND THE PRINCIPLE OF NEED}

Diverse theories of justice have been invoked to explain how actuarial fairness might conflict with moral fairness in the debate concerning the just use of GTRs. Space does not permit an exhaustive survey of this literature here, so I shall simply attempt to capture the core concerns that have been mobilised in support of this view within two broad principles of justice.

Some theorists have appealed to egalitarian principles of justice to counter the qualified support that the principle of equity lends to the use of GTRs. ${ }^{56}$ At the broadest level, the formal principle of equality states that 'like cases should be treated alike'; different theories of egalitarianism add different substantive content to this formal principle. But all such egalitarian principles are fundamentally comparative-what matters for justice on such principles is that one party is not at an unfair disadvantage relative to another. ${ }^{11}$ Call this the basic egalitarian concern.

Of course, egalitarians can endorse quite different views about what the 'currency' of egalitarianism should be; that is, they can disagree on what it is that egalitarian principles should seek to equalise. ${ }^{12} 13$ For instance, one substantial debate concerns whether such principles should seek to ensure equal levels of welfare or equal opportunities for welfare. ${ }^{14} 15$ Alternatively, other theorists claim that egalitarianism should primarily be concerned with the distribution of resources or capabilities. ${ }^{12} 16$

Another potential source of divergence among egalitarian principles is that egalitarianism can be grounded by different understandings of why inequality is bad. On what Parfit terms 'telic' egalitarian views, all unequal outcomes are intrinsically bad. ${ }^{11}$ However, egalitarian principles need not be committed to this claim. First, one might claim that there are certain conditions on inequality being intrinsically bad (for instance, that the inequality is harmful). ${ }^{17}$ Alternatively, it might be claimed that inequalities are instead only bad for extrinsic reasons, concerning the manner in which the inequality was produced. On such 'deontic' egalitarian views, inequality is only bad when it is produced by others in an unjust manner. ${ }^{11}$ iv Crucially, on these latter approaches, not all inequalities are necessarily bad, and differential treatment on the basis of some inequalities may be compatible with egalitarianism. For instance, for some so-called 'luck' egalitarians, differential treatment on the basis of inequalities that are a result of an individual's voluntary choice can be compatible with egalitarianism. The latter may only require that we redress those inequalities that arose as a result of certain kinds of luck. ${ }^{516}$

\footnotetext{
iv Some have questioned the exhaustiveness of Parfit's distinction between telic and deontic egalitarianism. See Mason, Scanlon, O’Neill. ${ }^{173132}$
} 
As such, there are myriad ways in which the formal principle of equality might be cashed out. On the assumption that access to insurance is an egalitarian concern across a range of egalitarian currencies, I suggest that we can phrase a broad principle of equality that aims to capture the basic egalitarian concern in this context as follows:

Principle of Equal Access: Differential access to insurance is bad unless it is grounded by an inequality that is not unjust.

This principle can first be applied to the general question of which model of insurance we should employ. Notice that it is compatible with the very strong claim that there are no inequalities that are not unjust, and that any differential access to insurance could be bad by egalitarian lights. Such an interpretation lends support to a social insurance model, but such a strong claim may be unappealing for deontic egalitarians. In applying the principle at this general level, we might also consider how the badness of this inequality fits into broader concerns about other forms of social inequality.

However, the principle is also compatible with the claim that some differential access to insurance is compatible with egalitarianism. Furthermore, it can also be applied to the narrower question of whether a given model of mutualistic insurance is compatible with egalitarianism. Indeed, the principle of equal access and the principle of equity would have the same implications if all inequalities between different individuals' risk profiles were not unjust. Yet, there are a number of reasons why egalitarians might argue that a particular inequality is unjust. As I mentioned above, permutations of luck egalitarianism might claim that inequalities in risk profiles are unjust when they are the result of certain kinds of bad luck. ${ }^{5}$ A luck egalitarian principle might thus deny that it would be fair to allow differential access to insurance on the basis of factors over which the individual does not exercise voluntary control.

Strong egalitarian views, which allow for fewer just inequalities that can ground justifiable differential access, can have significantly revisionary implications for the practice of insurance. However, as one narrows the scope of the principle of equal access by allowing for a greater number of inequalities that are not unjust, the more accommodating it becomes to the kinds of mutualistic insurance schemes we currently employ. Notably though, even a luck egalitarian interpretation of the equal access principle would have significantly revisionary implications; although it would accommodate a mutualistic scheme that takes into account increased health risks evinced by personal choices (such as smoking ${ }^{18}$ ), it would be unable to accommodate risk classification that takes into account other factors outside of the individual's genetic profile that are also beyond the individual's control, such as sex and age. Yet these are all factors that are commonly taken into account in mutualistic schemes. Even more pertinently in the current context, such schemes are not prohibited from using family history of a disease in actuarial decision-making. ${ }^{v}$ Clearly, an individual lacks control over her family history of a disease just as much as she lacks control over her genotype.

With respect to GTRs, it might be claimed that how we cash out the principle of equal access is somewhat moot, since there is no plausible sense in which being at increased risk of a genetic disorder is a 'just' inequality. However, luck egalitarianism has the

${ }^{\mathrm{v}} \mathrm{I}$ thank an anonymous reviewer for raising this point. theoretical apparatus to deny this. The reason for this is that it is rarely the case that a gene will cause an adverse health state in a manner that is causally independent of behaviours that an individual chooses. ${ }^{3} 5$ Accordingly, although strong egalitarian approaches might speak against the use of GTRs in risk classification, a luck egalitarian interpretation of the principle does not unequivocally support prohibiting differential access to insurance on the basis of all GTRs. ${ }^{3}$

The principle of equal access is a comparative principle, and it thus remains indifferent with respect to the absolute level of access that individuals should have to insurance. One striking implication of this is that the principle of equal access would alone provide little grounds for complaint if the prevalence of GTRs led to general adverse selection and market failure, if this affected everybody's access equally. This form of 'levelling down' suggests that a plausible account of justice in this context must also incorporate a non-comparative principle that enjoins social institutions to ensure that individuals meet a certain standard of whatever the correct currency of justice is. Call this the basic non-comparative concern. ${ }^{\mathrm{vi}}$

Of course, there is also a plethora of non-comparative principles of justice. To provide a necessarily brief sketch of the landscape in very broad terms, perhaps the most basic noncomparative principle is simple utilitarianism, which enjoins us to maximise well-being for the greatest number. ${ }^{19}$ vii Prioritarian principles maintain that the worse off someone is, the greater our moral reasons to benefit them. In judging how badly off someone is, we do not look to their situation compared with others, but to their absolute level of deprivation. ${ }^{11}$ Sufficientarian principles claim that justice should aim to ensure that individuals achieve a certain minimum threshold of whatever currency of justice the theory invokes. ${ }^{2021}$

These principles will sometimes converge on certain practical recommendations. For instance, the utilitarian might agree with the prioritarian that justice demands that we ought to give some benefit to the worst off instead of the better off in some cases. However, their justification for doing so will differ; while the prioritarian will justify this by appealing to the additional moral weight attached to benefiting the worst off, the utilitarian may do so by claiming that benefiting the worst off will lead to a greater increase in overall wellbeing (perhaps due to the effects of diminishing marginal utility). Furthermore, theories of justice can adopt hybrid non-comparative principles. For example, one might adopt a prioritarian approach below a threshold of sufficiency, and a utilitarian principle above that threshold. ${ }^{22}$

Even this basic overview is enough to show that various principles might be invoked to capture the basic non-comparative concern. Once again, my intention here is not to endorse a particular non-comparative view, but to outline a broad principle that accommodates the various ways in which the basic non-comparative concern can be captured:

Principle of Need: (i) Social institutions should aim to ensure that individuals' most basic needs are met, and (ii) aim to increase individual benefits (appropriately weighted) beyond that minimum threshold.

\footnotetext{
${ }^{\text {vi }}$ Some egalitarians reject the claim that the levelling down objection is a sufficient basis to reject their view. See Mason, Equality. ${ }^{1733}$

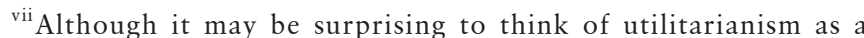
principle of justice, it is fundamentally a view about the morally right way to distribute benefits and burdens.
} 
This formulation of the principle is intentionally compatible with different non-comparative principles that have been invoked in the context of GTRs. In isolation, (i) outlines a sufficientarian approach. By virtue of (ii), the principle can accommodate the utilitarian thought that social institutions should go further and seek to maximise well-being. However, it is also compatible with prioritarian views, which claim that we should weight well-being such that benefiting people matters more the worse off they are, ${ }^{11}$ and even the Rawlsian thought that in some respects, social arrangements should be structured so as to benefit the worst off as much as possible. ${ }^{137}$

In some cases, parts (i) and (ii) of the principle may conflictthere may be some circumstances in which we could achieve a greater overall benefit for the better off, than we can for the worst off who fall below a threshold of sufficiency defined by need. In such cases, the utilitarian will claim that part (ii) of the principle should take precedence, while prioritarians and sufficientarians will claim that part (i) should take precedence. The utilitarian interpretation in such cases arguably renders the noncomparative principle outlined above to be less one of need per se, and more one of absolute benefit. However, the principle also accommodates the thought that in other cases, the implications of utilitarianism, sufficientarianism and prioritarianism can converge. My argument in the paper is intended to be compatible with quite different interpretations of what this principle demands.

The principle of need invites us to consider the broader consequences of permitting the use of GTRs in insurance for wellbeing. It has been claimed that permitting their use in insurace might threaten health needs indirectly, by reducing the number of people willing to undergo genetic testing. ${ }^{10}$ However, this argument has been challenged on the basis that (1) This has not been the case with other predictive medical tests ${ }^{23}$ and (2) It ignores the counteracting incentive that people might have to take a genetic test if they suspect that they have a low genetic risk. ${ }^{5}$

Yet, neither of these responses is unimpeachable; the first relies on the questionable assumption that the public will typically view GTRs as equivalent to other kinds of predictive test results. This assumption is thrown into doubt by data suggesting that belief in genetic exceptionalism is far from rare-indeed, in a recent study investigating layperson views on genomic data, around $52 \%$ of participants expressed exceptionalist views about genetic information. ${ }^{24}$ The second is overly optimistic about the extent of the incentive in question. Prior to testing, there is only a very small chance that any given asymptomatic individual will develop a serious genetic disease. In the absence of further information, it is rational for insurers to assume that a given asymptomatic individual poses a low risk in this regard, and to incorporate that into their calculation of an attractive premium to offer. If information from positive GTRs shows that this assumption is incorrect for a given individual, this gives the company a strong reason to substantially increase that individual's premium. In contrast, if negative GTRs merely confirm the absence of what was presumed to be a low risk, this does not lead to a comparably substantial decrease in the premium that it is rational for the insurance company to offer.

Notwithstanding the problems with this consequentialist argument, clause (1) of the principle of need lends straightforward support to social over mutual insurance schemes, and thus conflicts with the principle of equity (and its qualified support for the use of GTRs). ${ }^{37}$ The scope of the implications of this conflict depends on the extent to which (1) Access to a specific type of insurance constitutes a basic need, and (2)
Whether mutualistic insurance could be an acceptable way of increasing individual benefits beyond the provision of basic needs. Insofar as it adopts a social insurance scheme for health but a mutualistic scheme for life, critical illness and income insurance, the UK appears to adopt a mixed approach on these questions. The mixed approach might plausibly be justified by considerations of justice, if healthcare is taken to be a basic need in a way that financial support for critical illness or premature death is not. However, authors such as O'Neill have challenged this understanding of basic needs in the provision of insurance. ${ }^{6}$

Accordingly, on various interpretations, the principles of equal access and need lend considerable support to prohibiting the use of GTRs and favouring social insurance schemes. In that sense, O'Neill is correct to claim that there is considerable convergence about what social justice demands in this context. Yet, in some ways this argument proves too much; the implications of these principles of justice go far beyond the use of GTRs and call for fundamentally changing the UK's approach to many forms of insurance. Of course, we can have strong reasons to endorse revisionary conclusions if they receive strong pluralistic support. However, in the final section, I shall suggest that although O'Neill's argument receives considerable pluralist support, this support is not total; his claim that there is broad convergence on what social justice demands in the context of insurance overlooks an understanding of justice that affords greater prominence to the principle of equity.

\section{EQUITY, QUASI-LIBERTARIANISM AND THE CODE}

Justice is often understood to pertain primarily to the establishment of fair distributions. ${ }^{25}{ }^{26}$ However, libertarian approaches deny this, instead claiming that justice is predominantly concerned with ensuring that outcomes are produced in a manner that honours individual citizens' rights and fundamentally, their self-ownership. ${ }^{27}$ On the libertarian approach, requirements of justice may be quite distinct from questions about fair distribution.

A strictly libertarian approach to insurance would be just as revisionary as a strictly egalitarian approach. Existing insurance markets are highly regulated. Yet, libertarians are typically loath to accept restrictions on commercial transactions between consenting adults. Accordingly, it might be claimed that a strong libertarian approach would call for a largely unregulated market for insurance, in which market forces determined the prices of cover. $^{\text {viii }}$

Naturally, libertarian views will be particularly averse to social insurance schemes; accordingly, the principles of equality and need clash significantly with a libertarian approach to justice in this context, insofar as they support such schemes. However, the principle of equity is more amenable to libertarian views. First, as I suggested above, if one endorses a mutualistic rather than a social scheme for insurance (as the libertarian should), then the principle of equity should receive pluralistic support insofar as it protects such markets from general adverse selection. When the existence of a market for mutualistic insurance is compatible with libertarian interests, libertarians have some reason to endorse the principle of equity, insofar as the principle serves to safeguard the market. Second, and perhaps more importantly,

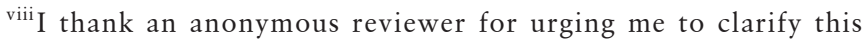
point. 
the principle safeguards a freedom that is likely to be central for the libertarian in the context of insurance, namely, the freedom to access advantages that accrue to individuals by virtue of their health status. This freedom is likely to be particularly important for the libertarian because it is intimately related to the notion of self-ownership that lies at the heart of many permutations of libertarianism. ${ }^{27}$

Accordingly, while a strict libertarian approach to insurance might eschew any form of regulation, or further moral principles governing insurance markets, there are what we might call quasi-libertarian grounds for insurance markets that observe the principle of equity. It is a principle that protects the existence of the market for a valuable good, and it does so in a way that does not infringe on a freedom that is particularly valuable for the libertarian. It runs counter to claim that low-risk individuals should pay premiums that effectively subsidise those at high risk, and instead allows for a market in which individuals are free to make their own choices about the level of risk they want to take, given their own particular circumstances.

This, I believe, means the principle of equity captures a core element of what libertarians might value in the context of insurance. If that is so, then we can see that O'Neill's claim that there is broad convergence on what plausible theories of justice demand in this context may overlook the quasi-libertarian support that the principle of equity can garner. I shall conclude by considering the implications of this conflict for the current UK policy.

Of course, one might be tempted to dismiss the quasi-libertarian approach as an implausible and incorrect understanding of what constitutes justice; indeed, this seems to be assumed in many philosophical discussions of the topic. However, it is a mistake to simply dismiss this understanding of justice without deeper engagement. Not only does this view plausibly buttress the systems of mutualistic insurance that are currently employed in the UK, it is also an understanding of justice that is implicit within the terms of the Code that I outlined in section I, and its commitment to actuarial fairness.

There are two more practical possibilities. First, one could argue that features of GTRs give us reasons to reassess which principles of justice ought to predominantly shape insurance arrangements. Perhaps we should abandon the principle of equity, and instead focus only on the principles of equality and need. However, as I have explained, such an approach would have highly revisionary implications for the way in which we implement insurance schemes. There are grounds for scepticism about the extent to which philosophical arguments will be sufficient to motivate this revisionary approach among policy-makers, especially given that there is room for reasonable disagreement about what justice may demand here. Second, one might acknowledge this theoretical conflict for what it is, and instead argue that a pluralistic society ought to reconcile the conflicts between the principles outlined above to the greatest extent possible, rather than ground crucial social arrangements on one contestable theory of justice. This second approach seeks to find a solution of compromise in the light of disagreement about what justice demands, as opposed to urging a particular answer to what justice ultimately requires of us. This, I believe, is a more promising strategy, and to conclude, I want to suggest that the UK's approach generally achieves this.

The principles outlined above have different implications for the question of whether, when, and how a mutualistic insurance scheme can be compatible with justice. The first point to note is that in providing healthcare on a social insurance model but allowing a market of mutualistic schemes for other goods (with certain limits on the risks that they can take into account), the UK effectively forges a compromise position between these principles across different forms of insurance, rather than adopting one principle as having absolute precedence in different kinds of insurance. Second, in the specific context of GTRs, we may note that the Code only permits the use of GTRs for claims over certain financial limits; this suggests that the quasi-libertarian flavour of permitting the use of GTRs in this context is in fact tempered by considerations related to the principles of equal access and need.

As I explained above, once one assumes that a mutualistic scheme is compatible with the demands of justice, considerations of actuarial fairness should receive pluralistic support as a guard against outcomes that are unfair on any plausible theory, in particular against the effects of general adverse selection. The use of GTRs in mutualistic schemes will thus receive pluralistic support if and when their use is necessary to guard against general adverse selection. I noted above that there are several reasons why many GTRs will not provide information that is necessary in this way. Accordingly, protection against general adverse selection calls for a sensitive testspecific approach to licensing the use of particular GTRs that have a sufficient degree of predictive power; this is just what the Code calls for, rather than blanket permission or prohibition.

However, in the precise letter of its current iteration, in which Huntington's disease is singled out as the only condition for which GTRs may be used, the Code appears to apply the principle of equity in a manner that implicitly relies on a controversial and solely quasi-libertarian justification, rather than one that will receive pluralistic support in the manner outlined above. Although the test for Huntington's disease plausibly meets criteria for information that is necessary for accurate risk classification, it is implausible to suggest that allowing the potential for an information asymmetry in the specific case of Huntington's disease would lead to general adverse selection of a sufficient scope to bring about effects that most theories of justice require us to prevent.

To see why, consider the numbers: between 1990 and 2010, the average incidence rate of Huntington's disease was 7.2 per million patient years; ${ }^{28}$ in contrast, 23.7 million protection insurance policies are currently in place in the UK. ${ }^{29}$ On these numbers, it is implausible to suppose that an information asymmetry regarding Huntington's disease places the market at risk of general adverse selection, even though it might lead to (a low number of) specific instances.

A solely quasi-libertarian interpretation of the principle of equity might lead one to conclude that even these specific instances of adverse selection would constitute injustice. However, if the terms of the Code are to be grounded by a pluralistic approach to justice, rather than a predominantly quasi-libertarian vein (in which each and every specific instance of adverse selection constitutes injustice), then permitting even the use of powerful predictive GTRs should currently be forestalled. Their use should be forestalled until such a time that powerfully predictive GTRs pertain to serious conditions that cumulatively affect enough people to seriously raise the prospect of general adverse selection, of the sort that is sufficient to bring about outcomes that would constitute injustice or unfairness on diverse understandings of justice.

Acknowledgements The author thanks Dr. Ben Davies and two anonymous reviewers for their comments on earlier versions of the manuscript, and the Uehiro Foundation for Practical Ethics for funding this research.

Contributors JP is the sole author.

Funding The Uehiro Foundation for Practical Ethics funded the research for this paper.

Competing interests None declared.

Patient consent for publication Not required. 
Provenance and peer review Not commissioned; externally peer reviewed.

Data availability statement There are no data in this work.

\section{REFERENCES}

1 Nill A, Laczniak G, Thistle P. The use of genetic testing information in the insurance industry: an ethical and societal analysis of public policy options. J Bus Ethics 2019;156(1):105-21.

2 Association of British Insurers, HM Government. Code on genetic testing and insurance, 2018. Available: https://www.gov.uk/government/publications/code-ongenetic-testing-and-insurance [Accessed 30 Jan 2020].

3 Feiring E. Reassessing insurers' access to genetic information: genetic privacy, ignorance, and injustice. Bioethics 2009:23(5):300-10.

4 Murray T. Genetic Exceptionalism and" Future Diaries: Is Genetic Information Different from Other Medical Information? In: Rothstein MA, ed. Genetic Secrets : Protecting Privacy and Confidentiality in the Genetic Era. Yale University Press, 1997: 60-73. https://scholar.google.com/scholar_lookup?hl=en\&publication_year=1997\&pages= 60-73\&author $=$ T. + H+Murray\&title $=$ Genetic+exceptionalism + and $+\% E 2 \% 80 \%$ 9CFuture+Diaries $\%$ E2\% $80 \% 9 \mathrm{D} \% 3 \mathrm{~A}+\mathrm{Is}+$ genetic+information+different+from+ other+medical+information

5 Lippert-Rasmussen K. Genetic discrimination and health insurance. Res Publica 2015;21(2):185-99.

6 O'Neill M. Genetic information, life insurance, and social justice. Monist 2006;89(4):567-92.

7 Daniels N. The Functions of Insurance and the Fairness of Genetic Underwriting. In: Rothstein MA, ed. Genetics and life insurance: medical Underwriting and social policy. Cambridge MA: MIT Press, 2004: 119-45.

8 Malpas PJ. Is genetic information relevantly different from other kinds of non-genetic information in the life insurance context? J Med Ethics 2008;34(7):548-51.

9 Wolf SM, Kahn JP, Working Group on Genetic Testing in Disability Insurance. Genetic testing and the future of disability insurance: ethics, law \& policy. J Law Med Ethics 2007;35(2 Suppl):6-32.

10 Rothstein MA. Time to end the use of genetic test results in life insurance Underwriting. J Law Med Ethics 2018;46(3):794-801.

11 Parfit D. Equality and priority. Ratio 1997;10(3):202-21.

12 Sen A. Equality of What? - University of Oxford. In: Sen A, ed. Choice, welfare, and measurement. Oxford: Basil Blackwell, 1982: 353-69. http://solo.bodleian.ox.ac.
uk/primo-explore/fulldisplay/TN_oxford_scholarship10.1093\%2F0198289286.003. 0002/SOLO

13 Dworkin R. What is equality? Part 1: equality of welfare. Philos Public Aff 1981;10(3):185-246.

14 Arneson RJ. Welfare should be the currency of justice. Can J Philos 2000;30(4):497-524.

15 Arneson RJ. Equality and equal opportunity for welfare. Philos Stud 1989;56(1):77-93.

16 Anderson ES. What is the point of equality? Ethics 1999;109(2):287-337.

17 Mason A. Egalitarianism and the levelling down objection. Analysis 2001;61(3):246-54.

18 Segall S. Health, luck, and justice. Princeton, NJ: Princeton University Press, 2009. https://ezproxy-prd.bodleian.ox.ac.uk/login?url=

19 Bentham J. Utilitarianism. London: Progressive Publishing Company, 1890: 29.

20 Frankfurt H. Equality as a moral ideal. Ethics 1987;98(1):21-43.

21 Casal P. Why sufficiency is not enough. Ethics 2007;117(2):296-326.

22 Equality CR. Priority, and compassion *. Ethics 2003;113(4):745-63.

23 Holm S. Should genetic information be disclosed to insurers? Yes. BMJ 2007;334(7605):1196

24 Middleton A, Milne R, Howard $H$, et al. Members of the public in the USA, UK, Canada and Australia expressing genetic exceptionalism say they are more willing to donate genomic data. Eur J Hum Genet 2020;28(4):424-34.

25 Rawls J. A theory of justice. rev. ED. Cambridge, Mass: Belknap Press of Harvard University Press, 1999: xxii+538.

26 Rawls J. Justice as Fairness: a restatement. Cambridge, Mass. ; London: Harvard University Press, 2001: xviii+214

27 Nozick R. Anarchy, state and utopia. New York: Basic Books, 1974: 367.

28 Wexler NS, Collett L, Wexler AR, et al. Incidence of adult Huntington's disease in the UK: a UK-based primary care study and a systematic review. BMJ Open 2016;6(2):e009070.

29 Wolffowitz E. Life insurance statistics: are UK residents well protected? 2020. Available: https://www.finder.com/uk/life-insurance-statistics [Accessed 25 Feb 2020]

30 Godard B, Raeburn S, Pembrey M, et al. Genetic information and testing in insurance and employment: technical, social and ethical issues. Eur J Hum Genet 2003;11 Suppl 2(2):S123-42.

31 Scanlon TM. Why does inequality matter? Oxford University Press, 2018: 1-170.

32 O'NEILL M. What should Egalitarians believe? Philos Public Aff 2008;36(2):119-56.

33 Equality TL. Priority, and the Levelling-Down Objection. In: Clayton M, Williams A, eds. The ideal of equality. Macmillan, 2000: 126-61. 